\title{
Astudillo, César (coord.), 2013, Instituciones electorales nacionales a debate, México, Tirant lo Blanch, $276 \mathrm{pp}$.
}

El libro coordinado por el doctor César Astudillo presenta una serie de colaboraciones escritas por expertos en derecho electoral, cada una de ellas recoge elementos trascendentales tanto teóricos como de su amplia experiencia práctica.

El esfuerzo encabezado por el doctor Astudillo es resultado de la coordinación del Instituto de Investigaciones Jurídicas de la UNAM con el acompañamiento del Instituto Internacional para la Democracia y la Asistencia Electoral, IDEA Internacional, este último a través del Programa de Cooperación y Asistencia Técnica México. Este esfuerzo académico fue oportuno ya que pocas veces se dan argumentos en el momento en que el debate nacional se produce, y las reformas se estaban discutiendo en el Congreso.

Es así como los principales expertos en la materia dan un amplio debate en torno a la propuesta Contenida en el Pacto por México de crear instituciones electorales, tanto administrativas como jurisdiccionales de carácter nacional, de la mano con una ley electoral única para toda la República mexicana. A continuación se presentan los principales argumentos a favor y en contra de la propuesta contenida en el Pacto por México en materia político electoral. 
La magistrada María del Carmen Alanís señala que en los últimos años la democracia electoral en México se ha consolidado en dos dimensiones, la primera en un aparato normativo cierto y conocido para los actores políticos; la segunda, una competencia real. De tal modo que lo que ahora se debe hacer es esbozar un modelo de entramado institucional posible sin romper con el federalismo (pp. 21 y 22).

Alberto Alonso Coria expone cuatro escenarios, todos con ventajas y desventajas pero con el común denominador de realizar una modificación en el nombramiento de los consejeros electorales de las entidades federativas, la cual, en todos los escenarios quedaría a cargo del Consejo General del INE (p. 39).

César Astudillo señala que el cambio debe traer aparejado una reforma constitucional al artículo 116 y 122 de la Constitución en las vertientes: institucional, autonomía presupuestal, autonomía reglamentaria, periodos en el cargo uniformes, incorporar prórroga de mandato, homologar las incompatibilidades prefuncionales, estipular la garantía económica, y determinar la inamovilidad (pp. 63-65).

Ricardo Becerra indica que se deben evadir las intransigencias soberanistas o centralistas que resultan cruciales para la competencia electoral, la fiscalización, la transparencia y la rendición de cuentas (pp. 69-71).

Jaime Cárdenas indica que se requiere un diseño constitucional diferente, que democratice y haga transparente el funcionamiento de los órganos constitucionales autónomos. Es necesario dotarlos de autonomía presupuestal para que nos sean rehenes de los congresos. Sin embargo, el cambio más importante tiene que ver con el método de elección de los titulares (pp. 89-91).

Para Francisco Guerrero Aguirre la Propuesta del Pacto por México es posible siempre y cuando se respete un mecanismo de construcción de la reforma electoral que comprenda las siguientes consideraciones: establecer canales de diálogo, establecer la competencia por temas, fiscalización, competencia por elecciones (pp. 135-139).

José Miguel Salcido dice que se debe evitar el juego de suma cero, por el cual las entidades federativas perderían lo que ganara la Federación. No se trata de configurar a los entes electorales locales como el enemigo que debe ser destruido, sino de fomentar, por todos los frentes posibles el apego al respeto de las reglas (pp. 251-257).

Oswaldo Chacón Rojas señala que existen muchos elementos fácticos que impiden la imparcialidad y con la creación del INE éstos no 
cambiarán. Existen factores empíricos institucionales o culturales que sobreempoderan a los gobernadores y debilitan los contrapesos de poder, por lo que hay muy pocas esperanzas de generar mejores condiciones de competencia en contextos de esa naturaleza (pp. 99-105).

El consejero Lorenzo Córdova señala que existen muchos problemas que enfrentarse antes de avanzar en la revolucionaria propuesta de crear un único órgano administrador de las elecciones en país. No se puede pretender que las actuales salas regionales del TEPJF subsuman la carga judicial que actualmente tiene los tribunales locales (pp. 113-115).

Alejandro Delint García considera inviable la creación de un Tribunal Nacional de Elecciones e impulsa la idea de mejor optar por un sistema contencioso jurisdiccional pensando en que en el ámbito federal el poder electoral supremo esté vinculado al Poder Judicial (p. 123).

Fernando Herrera señala que con la creación del INE se estaría ante un súper órgano público, con un presupuesto y poder muy considerables, al cual más valdría tener bajo control, pero el cómo ejercer ese control abre otra puerta a la sospecha, a la necesidad de revisar $\mathrm{y}$, por qué no, regresar (p. 144).

Para Carla A. Humphrey Jordan no es viable, conveniente, ni oportuno la desaparición o fusión de los órganos electorales en uno sólo que concentre el ejercicio de la función electoral en el país pues ello violenta el pacto federal y desconoce los avances de las autoridades electorales de las entidades federativas (pp. 160-163).

Aide Macedo Barcenas coincide con esa idea y señala que un verdadero federalismo en materia judicial electoral requiere fortalecer no sólo los ámbitos competenciales de los tribunales locales, sino también sus capacidades institucionales en relación con su imparcialidad y funcionalidad (p. 192).

Jesús Orozco Henriquez señala que la consolidación de la democracia electoral y la garantía efectiva de los derechos y libertades fundamentales político-electorales pasa, sin duda, por el fortalecimiento del federalismo judicial electoral (pp. 224-227).

Para Nicolás Loza no es necesario el INE, basta con elevar los estándares constitucionales y reglamentarios mínimos del funcionamiento de las autoridades en los estados, preservando sin embargo, la natura- 
o leza soberana local del conjunto de las autoridades electorales de los estados (pp. 177 y 178).

Para Rosa María Mirón Lince hoy en día tenemos un sistema electoral sólido y eficiente. La instrumentación de una reforma que modifique de raíz dicho sistema para centralizarlo conlleva grandes riesgos y consecuencias, por lo que es indispensable aquilatarla antes de que sea aprobada (pp. 209-212).

En el mismo sentido, Luis Carlos Ugalde señala que la creación del INE no contribuirá a solucionar los problemas centrales de la democracia electoral y porque el IFE ya hace bien sus funciones (pp. 261 y 262).

José Woldenberg señala que es más conveniente descargar al IFE $\mathrm{y}$ a los institutos locales de sus funciones como juez y reforzar a las instituciones administrativas encargadas de organizar las elecciones ciñéndolas a su papel y reforzar la vía jurisdiccional para resolver controversias (pp. 271-276).

Se invita a los lectores a realizar un ejercicio de reflexión sobre estos argumentos para tomar una posición y enriquecer el debate público aportando nuevas ideas para mejorar las propuestas ya que la participación ciudadana es importante en los ejercicios deliberativos en una democracia. 